\title{
Ensino de Química em diferentes contextos sociais $^{1}$
}

Chemistry teaching in different social contexts

Bruno Ferreira dos Santos ${ }^{2}$

\section{Resumo}

Este artigo apresenta o desenvolvimento de um programa de pesquisa sobre o ensino de Química orientado por um marco teórico da Sociologia da Educação, e discute seus principais resultados. Sob uma perspectiva de análise comparativa, as práticas pedagógicas de professores de Química que ensinam em escolas de diferentes contextos sociais foram caracterizadas por um conjunto de indicadores relacionados com as regras do discurso pedagógico e associadas às questões macros sociais de poder e de controle, de acordo com a teoria de Basil Bernstein. $\bigcirc$ artigo apresenta os resultados mais relevantes obtidos, destacando as características menos favoráveis à aquisição dos conhecimentos e competências científicas e que, muitas vezes, constituem as práticas observadas nas escolas onde estudam os estudantes mais carenciados do espectro social. Por outro lado, alguns resultados também demonstram que, ao alterar algumas dessas características, professores conseguem elevar o desempenho dos estudantes. Estes resultados trazem implicações para a formação de professores de Química e para as políticas públicas. Na parte final, discutemse os desdobramentos e direções para pesquisas futuras relacionadas com este programa.

Palavras chave: ensino de química; contexto social; discurso pedagógico

\section{Abstract}

This article presents the development of a research program on the teaching of chemistry guided by a theoretical framework of the Sociology of Education, and discusses its main results. Under a comparative analysis perspective, the pedagogical practices of teachers of chemistry teachers who teach in schools of different social contexts were been characterized by a set of indicators related to the rules of pedagogical discourse and were associated to the macrossocial issues of power and control, according to the theory by Basil Bernstein. The article presents the most relevant results obtained, highlighting the characteristics less favorable to the acquisition of scientific knowledge and skills, and which often constitute the practices observed in the schools where study the most needy students of the social spectrum. On the other hand, some results also show that, by altering some of these characteristics, teachers can increase student's performance. These results have implications for the education of chemistry teachers and for public policies. The final part discusses the further unfolding and new directions for future research related to this program.

Keywords: chemistry teaching; social context; pedagogic discourse.

\footnotetext{
${ }^{1}$ Versão ampliada de uma conferência apresentada durante o $15^{\circ}$ Simpósio Brasileiro de Ensino de Química SIMPEQUI, realizado de 7 a 9 de agosto de 2017 na cidade de Manaus, Brasil

2 Universidade Estadual do Sudoeste da Bahia | bf-santos@uol.com.br
} 


\section{Introdução}

Uma das características mais marcantes do Brasil é a sua imensa desigualdade social, evidenciada por diversos indicadores de concentração de renda ${ }^{3}$. Essa desigualdade, naturalizada por perversos mecanismos de exclusão, se reflete em um desigual acesso não somente aos bens materiais, mas também aos culturais. A educação, em todos os seus níveis, constitui um desses bens culturais cujo acesso e aquisição são distribuídos de forma desigual, seja em termos de localização geográfica, seja em termos de posição nas diferentes camadas sociais que compõem a sociedade (ROSÁRIO; DINIZ, 2008). Essa desigualdade educacional, entretanto, raramente é abordada como um objeto de estudo na pesquisa em educação científica. As razões para isso são variadas, e uma delas, talvez a principal, se relaciona com o fato de que a maior parte das pesquisas em educação científica se fundamenta em teorias oriundas do campo da Epistemologia e da Psicologia. Como tradicionalmente foi a Sociologia da Educação a disciplina que se ocupou dos fenômenos associados às desigualdades social e educacional, sua ausência como marco teórico nas pesquisas em educação científica nos inibe de investigar como esta é distribuída entre a população estudantil e contribui para a produção/reprodução de nossas desigualdades.

Embora a desigualdade educacional na educação científica, compreendida aqui como o acesso e a distribuição diferenciadas de conhecimento escolar entre distintos grupos sociais pela educação formal, também possa ser considerada como um tema periférico da pesquisa nos chamados países desenvolvidos, esta condição tem se modificado à medida que emergem problemas associados à imigração e à inclusão de grupos tradicionalmente excluídos nessas sociedades. Questões como o multiculturalismo e o ensino para estudantes que não têm o idioma oficial como primeira língua passaram a ser investigadas nas duas últimas décadas. Desse modo, os estudos sobre a linguagem, o discurso e a cultura entendida em sua forma mais ampla, e suas relações com o ensino e a aprendizagem em ciências adquirem uma maior presença na agenda da pesquisa em educação científica nestes países.

No Brasil, os exames sobre aprendizagem e desempenho destacam a associação entre a origem socioeconômica e o rendimento dos estudantes. A família e os lares dos escolares são variáveis que incidem sobre as suas trajetórias acadêmicas, como provedora do capital cultural vinculado ao desempenho escolar ${ }^{4}$. Nossa estratificação social joga desfavoravelmente quanto a este aspecto, uma vez que somente nas décadas recentes atingimos a universalização da escola básica. Isto significa que em muitas famílias, os pais e responsáveis apresentam níveis de escolarização inferiores aos que a sua prole está adquirindo, o que sem dúvida constitui uma condição de partida deficitária para os estudantes destas famílias ao ingressarem e permanecerem na escola. À escola cumpriria então a difícil tarefa de tentar suprir este déficit, permitindo que seus alunos adquirissem, ao

\footnotetext{
${ }^{3}$ De acordo com o Relatório de Desenvolvimento Humano publicado pelas Nações Unidas, o Brasil está em $10^{\circ}$ lugar entre as nações mais desiguais do mundo, considerando-se a disparidade de renda. Ver matéria do jornal O Globo publicada em 21/03/2017, disponível em <<https://oglobo.globo.com/economia/brasil-o-10-pais-maisdesigual-do-mundo-21094828>>, consultado em 18/09/2017.

${ }^{4}$ A noção de capital cultural surge na obra de Pierre Bourdieu para explicar a desigualdade de rendimento escolar de estudantes oriundos das diferentes classes sociais. A este respeito consultar Bourdieu (2013).
} 
longo de sua trajetória, condições mais equânimes de aprendizagem e de desempenho que facilitassem seu acesso ao ensino superior e a melhores posições no mercado de trabalho que a de seus pais, de modo a romper o ciclo da reprodução da pobreza e da desigualdade.

Partindo destas considerações, iniciamos no ano de 2012 um projeto de pesquisa, posteriormente desdobrado em outros subprojetos derivados do primeiro, intitulado "Ensino de Química em diferentes contextos sociais", cujo objetivo principal era mapear as características do ensino escolar de Química em escolas cujos estudantes apresentassem perfis socioeconômicos distintos entre si, e tentar vincular as características observadas com o desempenho dos estudantes. As unidades de análise desta pesquisa foram as interações discursivas entre professores e estudantes ao redor do conhecimento químico e das relações sociais estabelecidas entre eles em sala de aula. Por meio de nossas análises, pretendíamos verificar as condições mais favoráveis ao ensino e à aprendizagem em Química, considerando o contexto social como uma variável, algo que julgávamos ausente (ou presente de forma muito tímida) nas pesquisas produzidas no Brasil.

Este artigo apresenta alguns dos resultados mais relevantes obtidos nas pesquisas que realizamos até o momento. Nele, apresentamos inicialmente o marco teórico-metodológico com o qual nos orientamos para, em seguida, discutir algumas das pesquisas já concluídas. $\mathrm{Na}$ última parte, indicamos como pretendemos seguir investigando as relações entre o contexto socioeconômico dos estudantes e o ensino e a aprendizagem da Química escolar, com base na identificação das lacunas e perguntas originadas nos estudos que até então logramos desenvolver. Todas as pesquisas discutidas neste artigo obedeceram as diretrizes estabelecidas pelo Comitê de Ética de nossa universidade, como o consentimento e esclarecimento dos sujeitos investigados e o compromisso com a confidencialidade de suas identidades.

\section{A sociologia da educação e o ensino de ciências}

Dentre as chamadas teorias da reprodução, desenvolvidas a partir dos anos $1960 \mathrm{em}$ diante, a teoria dos códigos pedagógicos proposta por Basil Bernstein ${ }^{5}$ buscou responder à questão sobre como o dispositivo pedagógico que opera no interior das escolas é capaz de perpetuar as desigualdades que existem fora dessas instituições. Para este autor, sem essa compreensão, as escolas são vistas como uma espécie de "caixa preta", ou seja, um sistema de entrada e saída dos estudantes que reproduz as relações de poder externas a ela. Segundo Bernstein, constitui uma tarefa da Sociologia elucidar a conformação do discurso pedagógico de modo a entender os processos de diferenciação e estratificação internos ao aparelho escolar, para que possamos relacioná-lo com as relações externas de poder e de controle presentes na sociedade.

No desenvolvimento de sua teoria, duas importantes características se sobressaem: Bernstein ambicionava que os conceitos propostos para o estudo dos códigos e do discurso pedagógico fossem capazes de permitir análises tanto em uma dimensão macrossociológica como em uma dimensão micro, como o são as interações em sala de

\footnotetext{
${ }^{5}$ Breves introduções à obra de Basil Bernstein são encontradas em Santos (2003), em Morais e Neves (2007) e em Mainardes e Stremel (2010).
} 
aula, objeto de nossos estudos. Ele também indicava que uma teoria social deveria desenvolver duas linguagens, uma interna que diz respeito aos modelos teóricos, e uma externa, que permite a conexão entre os modelos e conceitos teóricos e o mundo empírico. É por meio dos conceitos de classificação e de enquadramento e de sua operacionalização analítica que se vinculam as noções macrossociológicas de poder e de controle com as práticas interativas em sala de aula (BOHLMANN; GELLERT; STRAEHLER-POHL, 2017).

Por meio da classificação se examinam as fronteiras ou o isolamento entre as diferentes categorias, como os agentes, os discursos e as práticas, como, por exemplo, a separação entre a disciplina Química e as demais disciplinas científicas presentes no currículo do Ensino Médio. Quando as práticas pedagógicas incluem instâncias de interdisciplinaridade entre os conteúdos e competências ligados a estas disciplinas, tem-se um grau de classificação fraco; quando as práticas distanciam os conteúdos e competências, trabalhando-os sem estabelecer conexões e vínculos, tem-se um grau de classificação forte. Já o enquadramento, que faz referência às relações sociais dentro de um determinado contexto, permite analisar o controle sobre a comunicação nas interações entre os agentes ou sujeitos: no caso da relação pedagógica entre professores e alunos, tem-se um grau de enquadramento forte quando o professor, que ocupa a posição hierárquica de maior status, assume um controle explícito sobre as dimensões da prática instrucional; em um grau de enquadramento fraco, este controle é compartilhado com os alunos, ainda que o controle por parte dos alunos possa ser somente aparente.

As pesquisadoras portuguesas Ana Maria Morais e Isabel Pestana Neves, do grupo ESSA $^{6}$ - Estudos Sociológicos da Sala de Aula -, vinculado à Universidade de Lisboa, são as responsáveis por aproximar a teoria sociológica de Basil Bernstein da pesquisa em educação científica. Por meio de inúmeros estudos, este grupo vem desenvolvendo e aperfeiçoando uma linguagem externa de descrição baseada na teoria Bernsteiniana, especialmente sob a forma de um conjunto de indicadores empregados na análise dos graus de enquadramento e de classificação da prática pedagógica no ensino de ciências e de Biologia em escolas portuguesas. Além disso, suas investigações incluem estudos sobre a exigência conceitual, sobre a intervenção na forma da pesquisa-ação e também sobre a formação de professores de ciências e Biologia.

Os indicadores empregados pelo grupo ESSA fazem referência às duas modalidades de discurso - o instrucional e o regulador - que juntos compõem o discurso pedagógico, de acordo com a teoria de Bernstein. Para ele, o discurso pedagógico é um discurso sem conteúdo próprio: é o resultado da ação do princípio de recontextualização, que desloca discursos produzidos em outras instâncias, como o da Química acadêmica e aqueles das teorias sobre a aprendizagem, por exemplo. Bernstein (1990) discute essa relação com respeito à Física: "Las relaciones sociales y de producción de la física en su campo de producción, allí donde se hace y se cambia la física, son tales que es imposible derivar de ellas la 'física' que se enseña en las escuelas" (p. 108). Estes, uma vez deslocados e apropriados pelo discurso pedagógico, irão definir o que ensinar e o como ensinar, de tal forma que em seu transporte e relocalização no discurso pedagógico irão projetar representações ideológicas sobre os aprendizes, definindo a ordem no discurso regulador

\footnotetext{
${ }^{6}$ O grupo mantém uma página na rede webno endereço eletrônico <<essa.ie.ulisboa.pt>> com informações e publicações disponíveis.
} 
(por meio das chamadas regras hierárquicas) o qual, por sua vez, submete as regras do discurso instrucional (conhecidas como regras discursivas). Portanto, de acordo com Bernstein, o discurso regulador é sempre o discurso dominante em relação ao instrucional.

As regras do discurso instrucional coincidem com os saberes e competências didáticas dos professores (SANTOS; SANTOS, 2017) e constituem um conjunto de quatro regras: a seleção dos conteúdos, das competências e atividades; a sequência destes na organização do ensino; o ritmo ou o compassamento da prática pedagógica, que leva em consideração a aquisição dos conteúdos e competências pelos aprendizes; e os critérios de avaliação, por meio dos quais os professores avaliam as produções dos aprendizes. O controle sobre estas regras é definido pelo grau de enquadramento da prática pedagógica. Juntamente com as regras hierárquicas, essas regras estabelecem para os estudantes aquilo que eles devem aprender e produzir para serem bem sucedidos. Sua variação em diferentes práticas dará origem ao chamado código pedagógico, cuja aquisição dependerá do domínio, pelos aprendizes, das regras de reconhecimento, por meio das quais os diferentes contextos da prática são reconhecidos, e das regras de realização, por meio das quais os estudantes serão capazes de produzir o texto (entendido aqui de forma ampla) esperado (BERNSTEIN, 2003).

A obra e a teoria de Bernstein vão muito além do que está apresentado aqui, porém este conjunto de conceitos permite o escrutínio de práticas pedagógicas em Ciências e sua relação com questões de aprendizagem e da relação com o contexto social mais amplo em que essas práticas estão inseridas. Baseados nestes conceitos e em seu uso nas pesquisas do grupo ESSA, realizamos um conjunto de investigações sobre o ensino de Química em diferentes escolas, com o objetivo maior de caracterizar essas práticas verificando a influência dos contextos nas interações em sala de aula. Iremos discutir em seguida os resultados mais destacados obtidos até o presente momento.

\section{A importância dos critérios de avaliação para a prática pedagógica de química}

Segundo Bernstein, os critérios podem ser explícitos e específicos:

"la pedagogía opera haciendo explícito al niño lo que falta en el producto, entonces los criterios siempre habrán de ser explícitos y específicos y el niño estará siempre consciente de estos criterios. (...)Sin embargo, los criterios pueden ser implícitos, múltiples y difusos" (BERNSTEIN, 1990, p. 74).

Quando os critérios são implícitos, os adquirentes não estão informados sobre os critérios que devem cumprir, a não ser de uma forma muito genérica. Nossa pesquisa, em sua fase inicial, colocou ênfase na análise da explicitação dos critérios de avaliação por professores de Química durante a definição de atividades e tarefas. Com isso, deslocamos o olhar das interações discursivas ao redor do ensino dos conceitos científicos, objeto privilegiado nas pesquisas sobre a linguagem e o discurso, em direção a outros momentos das aulas, que consideramos fundamentais para a aprendizagem, visto que se relacionam com as produções textuais dos estudantes (SANTOS, 2014).

Como nossas pesquisas se caracterizam por uma abordagem predominantemente qualitativa, a observação, o registro e a análise comparativa entre os dados constituem 
nossos métodos e técnicas de investigação. As observações iniciais de salas de aulas de Química em escolas cujos estudantes possuem origem socioeconômica diferenciada derivaram em um mapeamento das atividades e tarefas comuns que os professores realizavam. De posse desse levantamento prévio, passamos então a compará-las entre si, buscando caracterizar os modos de instrução privilegiados em cada situação de ensino. Os resultados dessa análise revelaram uma correlação entre a explicitação dos critérios e o ritmo da prática pedagógica: na escola particular, cujos estudantes pertenciam a famílias de condições mais estabilizadas, o professor dispunha de quatro aulas semanais para desenvolver um currículo muito semelhante àquele que os professores das escolas públicas observados tentavam desenvolver em apenas duas aulas por semana (SANTOS, 2015).

De um modo geral, essa correlação implica que, ao impor um ritmo mais acelerado à prática, os professores permitem menores espaços e tempos para a participação dos alunos durante a definição das atividades e tarefas. Como resultado, os alunos possuem pouca oportunidade para expressar suas dúvidas e questionamentos com respeito às tarefas que devem cumprir, recebendo menos informação sobre como conduzir as atividades e como produzir seus textos, quando comparados com os alunos da escola particular. Sem a posse dos critérios, no limite os estudantes em alguns casos nem realizavam as tarefas, o que levava seus professores a interpretar sua atitude como um relaxamento ou mesmo falta de interesse pela disciplina (SANTOS; SANTOS; SILVA, 2014).

\section{A exigência conceitual de um professor de química que ensina em escolas de contextos sociais distintos}

Uma segunda pesquisa que acompanhou a primeira examinou o caso de um mesmo professor que ensinava em escolas de perfis socioeconômicos distintos: uma escola privada que atendia alunos oriundos da classe média e uma escola pública situada em um bairro periférico, cuja maioria dos alunos habitava em seu entorno. Neste estudo investigamos a exigência ou demanda conceitual do professor desenvolvida em turmas do primeiro ano do Ensino Médio em ambas as escolas. A noção de exigência conceitual, desenvolvida pelo grupo ESSA (MORAIS; NEVES, 2016), compreende um conjunto de elementos da prática pedagógica e inclui a análise das regras discursivas, das relações interdisciplinares (entre os conteúdos de diferentes disciplinas), das relações intradisciplinares (entre os conteúdos da mesma disciplina), da relação entre o conhecimento acadêmico e o não acadêmico e as competências científicas do professor.

O resultado mais relevante observado em nossas análises da exigência conceitual dizia respeito às competências científicas nos exames realizados com os estudantes (SOUZA; SANTOS, 2016). Nestes, o nível de complexidade das questões variou entre uma escola e outra, sendo maior na escola privada comparado com o nível das questões da escola pública. Essa diferença se refletia não somente nas competências cognitivas que os estudantes tinham que desenvolver para responder às questões, mas também para interpretar os enunciados e os dados que algumas questões apresentavam. As imagens de moléculas representadas nos enunciados, bem como as tabelas que deveriam ser interpretadas apresentavam níveis mais complexos e mais abstratos nas questões da escola privada do que nas da escola pública, como ilustrado pela Figura 1, extraída dos exames aplicados. 

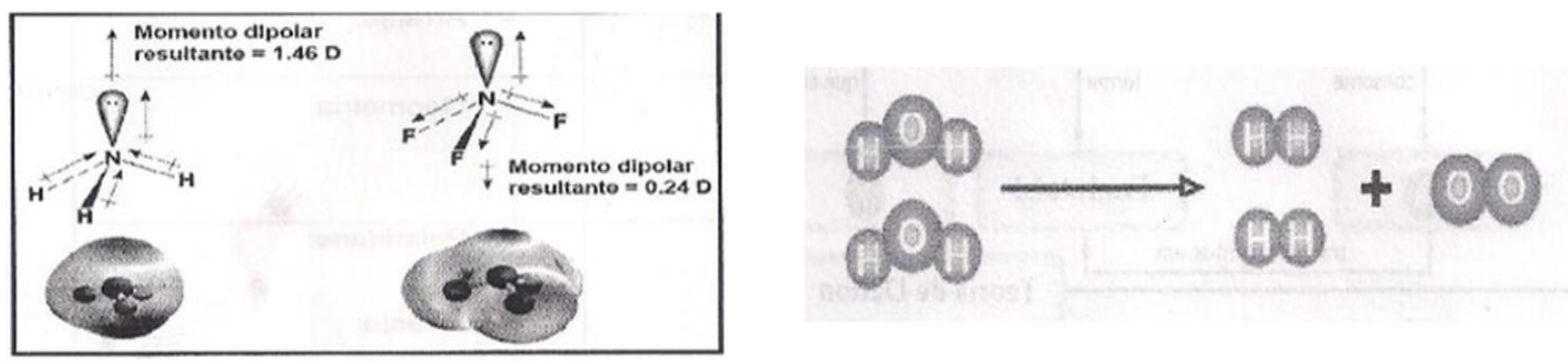

Figura 1: Imagens de enunciados de questões de exame na escola privada (esquerda) e na escola pública (direita). (Fonte: Extraído das avaliações realizadas nas escolas visitadas)

Outro aspecto nos chamou a atenção durante as observações nas duas escolas: os alunos da escola pública, de um modo geral, eram muito menos participativos nas interações do que os da escola privada. Esta característica nos levou a investigar as trocas discursivas entre o professor e seus alunos, e nos dirigiu o olhar para as perguntas que eram realizadas nestes intercâmbios. Nossa hipótese era que, como a expectativa do professor com respeito ao desempenho dos alunos das duas escolas parecia não coincidir, haja visto o resultado da análise das questões dos exames, este pudesse também elaborar questionamentos mais simples durante seu discurso, desestimulando a participação de seu alunado na escola pública em comparação com as perguntas durante os interações na escola privada.

O levantamento dos questionamentos nas trocas discursivas, tanto do professor como dos alunos em ambas as escolas confirmou uma participação significativamente maior tanto do professor como dos estudantes nestes intercâmbios na escola privada quando comparado com a escola pública. Com respeito ao nível da exigência cognitiva das perguntas do professor, em ambas as escolas predominaram os questionamentos mais simples, cujas respostas raramente vão além de uma única palavra. Já em relação aos questionamentos dos alunos, estes apresentaram, na escola privada, perguntas que exigem como resposta uma opinião ou a elaboração de um conceito, ou seja, de um nível cognitivo maior em uma frequência superior aos questionamentos dos alunos da escola pública. Como estes alunos elaboravam mais perguntas durante os intercâmbios, isto implicava que em um número maior de situações observadas o professor prolongava suas interações, fornecendo mais informações sobre os conteúdos que nos intercâmbios com os estudantes da escola pública. Nesta última escola, na maioria dos questionamentos dos estudantes a resposta do professor era mais direta, e ele explorava pouco essas situações de modo a prolongar o diálogo (SILVA; SOUZA; SANTOS, 2018).

\section{A pedagogia mista e a prática pedagógica de uma professora de química}

As investigações do grupo ESSA buscam identificar quais as características mais favoráveis da prática pedagógica para a aquisição de conhecimentos e competências científicas por todos os estudantes. Estes estudos levaram as pesquisadoras portuguesas a sugerir que o efeito da prática pedagógica é capaz de se sobrepor ao efeito da origem social dos estudantes, por meio de um modelo de pedagogia mista, para uma 
aprendizagem científica, social e afetiva bem-sucedida (MORAIS; NEVES, 2001). As condições para uma prática pedagógica mista incluem critérios de avaliação bem explícitos, um enfraquecimento do ritmo e da sequência da prática pedagógica, e uma alteração da classificação do espaço da sala de aula, permitindo uma maior aproximação entre o professor e os alunos, entre outras características.

Este conceito nos sugeriu uma pesquisa que objetivou identificar as aproximações e os afastamentos da prática pedagógica mista de uma professora de Química cujos alunos apresentavam um bom desempenho. Uma vez definidos os critérios de seleção, localizamos uma escola pública bem conceituada em nossa cidade, que apresentava os melhores índices nas avaliações externas, e cujos estudantes participavam ativamente e com destaque nas olimpíadas estaduais de Química. Outra característica desta escola que contribuiu positivamente para nossa pesquisa era uma maior integração entre alunos de diferentes classes sociais, dado levantado por meio de questionários socioeconômicos que realizamos em todas as nossas pesquisas. Este aspecto em particular aproximava a escola investigada dos cenários portugueses nos quais o grupo ESSA realiza suas próprias pesquisas.

Acompanhamos por uma unidade letiva as aulas em duas turmas do segundo ano do Ensino Médio. Os resultados de nossa análise permitiram avaliar o quanto a prática pedagógica da professora em questão se aproximava ou se afastava das características de uma pedagogia mista. Em ambas as turmas, sua prática se distanciava das características deste modelo proposto pelas pesquisadoras portuguesas, e se identificava muito mais com o modelo dito "tradicional", com fortes graus de enquadramento para as regras discursivas e hierárquicas. O que se destacou nas análises foi derivado da comparação de sua prática entre as duas turmas observadas: em alguns aspectos sua característica de forte enquadramento se intensificava em uma das turmas, o que significava um maior distanciamento do modelo quando comparado com a prática na outra turma (SANTOS; TRINDADE; SANTOS, 2016).

Quando confrontamos os perfis das duas turmas observadas encontramos algumas diferenças entre elas e que nos sugeriram uma explicação para o comportamento da professora. A turma do segundo ano na qual a professora intensificava as características de forte controle em sua prática era uma turma que apresentava alguns alunos repetentes e um perfil socioeconômico ligeiramente inferior (quando observávamos, entre outros elementos, a profissão e o grau de escolarização dos pais dos estudantes por meio do questionário). A outra turma, por sua vez, não tinha alunos repetentes. Essa distribuição dos estudantes do mesmo ano letivo por turmas nas escolas está longe de ser aleatória: ela obedece a critérios que homogeneízam as classes, reunindo os estudantes de acordo com certos perfis. Dessa forma, não é incomum a segregação entre os estudantes por seu rendimento dentro dos estabelecimentos escolares.

No caso investigado por nós, a turma que continha alunos repetentes representava aquela que a professora enfrentava mais freqüentemente situações de indisciplina e de conversa paralela. Sua forma de reagir a essas situações era fortalecer o controle, elevando os graus de enquadramento em sua instrução. Os estudantes desta turma, por consequência, eram submetidos a uma prática, de acordo com o modelo da pedagogia mista, mais desfavorável à aquisição dos conteúdos e competências científicas. Sua condição de partida como alunos de menor rendimento e desempenho acadêmicos era reforçada por uma prática centralizada na professora, com pouco espaço para a 
participação dos alunos no discurso em sala de aula. Essa condição nos revelava um quadro de desigualdade interna à escola, fenômeno ainda pouco investigado (SANTOS, 2016).

\section{Uma intervenção na prática pedagógica de uma professora de química}

As características observadas na prática pedagógica da professora da pesquisa anteriormente descrita parecem se reproduzir em muitas escolas públicas brasileiras, especialmente por aqueles professores compromissados com sua profissão, que assumem a tarefa de ensinar Química com dedicação e responsabilidade. As condições para o exercício da docência e a formação de professores, no entanto, atuam desfavoravelmente para a introdução de práticas pedagógicas mais propícias à aquisição, por todos os estudantes, dos conhecimentos e competências científicas. O extenso currículo da Química no Ensino Médio $^{7}$ é uma dessas condições limitantes: estes professores, na maioria das vezes, imprimem um forte ritmo em suas práticas de modo a cumprir os programas desta disciplina. Esta característica, conforme vimos em nossa primeira pesquisa, desfavorece justamente os estudantes mais carenciados, pois estes ficam privados de situações de intercâmbios com seus professores, e as aulas se transformam em um permanente monólogo no qual somente o professor fala e os alunos escutam e tomam notas. Seu acesso ao texto privilegiado no ensino de Química é limitado à voz do professor.

Outra pesquisa realizada pelo nosso grupo desenvolveu uma intervenção na prática pedagógica de uma professora de Química, cujas características se aproximavam bastante da descrição acima: grande controle sobre os elementos do discurso instrucional e regras hierárquicas com forte enquadramento, o que significa, entre outros aspectos, um distanciamento entre o espaço e a posição da professora frente a seus alunos. Nesta intervenção, a professora buscou alterar algumas dessas características junto a uma turma de primeiro ano do Ensino Médio, em uma escola situada em um bairro periférico que atendia alunos de baixo perfil socioeconômico. Em outra turma, chamada de turma controle, a professora ministrava as aulas seguindo o modelo de sua prática habitual. A turma controle constituía, na distribuição institucional realizada pela própria escola, a turma dos alunos mais "comportados", sendo a outra turma a que incluía alguns estudantes repetentes e aqueles considerados mais "difíceis" pela direção escolar. Como a professora era também a pesquisadora, ela preferiu não realizar a investigação em sua própria escola, e escolheu outra para o seu desenvolvimento. Em todas as aulas ministradas, que envolveram uma unidade letiva, ela foi acompanhada pela professora regente, que, no entanto, somente a observava durante a intervenção (SILVA; SANTOS, 2018).

As modificações que a professora realizou em sua prática abrangeram um enfraquecimento das regras hierárquicas, o que a levou a assumir um controle sobre o comportamento dos alunos mais pessoal e menos impositivo; um enfraquecimento do enquadramento para as regras discursivas seleção, sequência e ritmo; e um fortalecimento da regra critérios de avaliação. Os resultados observados claramente indicaram os

\footnotetext{
${ }^{7}$ Estamos aproximando a noção de currículo de programa ou plano de estudos, sem atribuir o sentido de uma prescrição oficial para o ensino disciplinar de Química.
} 
benefícios para o desempenho dos estudantes em sala de aula: eles se tornaram mais interessados pela matéria, mais participativos ao realizar perguntas e intervenções, ao mesmo tempo em que surgiam intercâmbios e discussões entre os próprios alunos, além de passarem a se dedicar mais às tarefas propostas e a indisciplina e os comportamentos indesejados diminuíram marcadamente. Os efeitos desta intervenção foram percebidos para além de seu término, pois a professora regente nos informou, alguns meses após nossa saída da escola, que as mudanças no comportamento dos estudantes da turma em que a professora pesquisadora modificou as características de sua própria prática eram ainda notáveis. Segundo seu relato, os estudantes continuaram a intervir com mais frequência e continuavam a se dedicar mais às tarefas da disciplina, quando se comparava seu comportamento com aquele anterior à intervenção (SILVA, 2015).

\section{Professores de química que também ensinam física e sua exigência conceitual}

Os relatos das duas últimas pesquisas que apresentamos trazem implicações para a formação de professores de Química e de outras disciplinas científicas. No primeiro, discutimos uma investigação que envolveu a observação e a caracterização da prática pedagógica de dois professores licenciandos em Química que também ministram aulas de Física. Ela teve como objetivo a comparação da exigência conceitual de suas práticas ao ministrarem ambas as disciplinas. Identificamos dois professores que se enquadravam nos critérios estabelecidos, e os estudantes de suas escolas apresentavam perfis socioeconômicos levemente diferenciados, um mais próximo das camadas sociais médias e outro das camadas mais economicamente desfavorecidas. As escolas também eram públicas e as observações abrangeram uma unidade letiva de cada disciplina no primeiro ano do Ensino Médio.

Os resultados de nossas análises evidenciaram que as características das práticas pedagógicas dos professores se reproduziam ao ensinar ambas as matérias, com diferenças mínimas em poucos elementos desta prática. Um dos aspectos que mais nos chamou a atenção foi a total ausência de relações interdisciplinares, que poderiam ser exploradas envolvendo conteúdos das duas disciplinas. Essa ausência também se repetia com respeito às relações intradisciplinares e ao baixíssimo uso de conhecimento não acadêmico, uma vez que o discurso instrucional se mantinha, na maior parte do tempo, exclusivamente ao redor do conhecimento científico. Mesmo as competências científicas das atividades e dos exames realizados não mostraram variação, sendo exploradas questões de baixo nível de abstração e de capacidade cognitiva. Ao considerarmos que os professores foram socializados em Química, esperávamos que pelo menos este aspecto de suas práticas revelasse alguma alteração entre uma matéria e outra (SOUZA; SILVA; SANTOS, 2017).

Interpretamos estes resultados como consequência da formação inicial destes professores, a qual, por destinar tão pouco espaço para uma formação em conteúdos e competências didáticas e pedagógicas, termina preparando professores que não problematizam nem adaptam sua prática à disciplina que ensinam, aplicando e desenvolvendo métodos de ensino que se supõem, de algum modo, universais, ou seja, à prova do conteúdo a ser ensinado. A presença no currículo da formação inicial de algumas disciplinas com conteúdos de Física leva os sistemas de ensino a considerar que professores 
formados em Química (ou em outra licenciatura que compartilhe essa característica) também seriam capazes de ensinar Física, uma prática disseminada na escola brasileira e que só reforça aquela suposição da existência de modelos universais para ensinar matérias diferentes de sua formação inicial (SOUZA, 2017).

\section{O papel do estágio supervisionado na aquisição de saberes e competências didáticas do professor de química}

Nesta pesquisa, acompanhamos um grupo de licenciandos em Química durante sua regência no Ensino Médio em escolas públicas na disciplina Estágio Supervisionado. Objetivávamos compreender como a experiência da regência proporcionava a aquisição de saberes e competências didáticas para esses professores em formação inicial. O estudo foi realizado por meio da caracterização do enquadramento das regras discursivas apresentados por eles, tratando de entender, entre outros aspectos, como os diferentes contextos em que desenvolviam suas práticas pedagógicas influenciavam na aquisição dos saberes e competências. Também foram acompanhados os encontros na universidade com a professora supervisora, realizadas entrevistas semiestruturadas com os licenciandos para conhecer sua trajetória acadêmica e levantar informações sobre as condições da regência e, por fim, analisados os planos de aula desenvolvidos por eles.

Entre os resultados obtidos, destacamos o papel do professor regente da escola no acompanhamento do estagiário como um fator fundamental para a aquisição dos saberes didáticos. Além disso, a autonomia do licenciando com respeito ao planejamento e execução de sua regência, bem como seu envolvimento e convívio nas instâncias escolares de discussão com os demais professores constituíram elementos cruciais para o desenvolvimento de práticas com características mais favoráveis para os alunos das escolas onde realizaram seus estágios. A experiência prévia como docente não figurou como um elemento diferenciador, pois alguns estagiários sem essa experiência e que contavam com o suporte do professor supervisor se desempenharam melhor que outros que já a possuíam (SANTOS; SANTOS, 2017).

Como contraponto, nas entrevistas realizadas raramente os estagiários identificavam o curso da licenciatura como o local da aquisição dos saberes e competências didáticas, porém indicavam que era o próprio exercício da docência o campo em que se os adquire. Este aspecto negativo reforça a ideia de senso comum de que "aprender a ser professor se aprende ensinando" e leva à reprodução de modelos de ensino conservadores e tradicionais pelos licenciandos. Essa suposição dos professores em formação também evidencia o menor status dos conhecimentos pedagógicos na licenciatura em Química com relação aos saberes disciplinares, e sua dificuldade em serem socializados dentro do discurso das ciências da educação além do discurso da própria Química, com o qual se identificam com muito maior adesão que àquele (SANTOS, 2017).

\section{Algumas considerações finais e implicações}

As pesquisas desenvolvidas até o momento, dentro de um programa que investiga o ensino de Química orientado por um marco teórico da Sociologia da Educação, revelaram diversas características da prática pedagógica de professores. A análise das regras 
discursivas e hierárquicas e da exigência conceitual fornece importantes subsídios para a reflexão sobre o ensino de Química que é praticado nas escolas públicas e particulares. As diferenças observadas por meio do estudo comparativo, ainda que careçam de representatividade estatística, têm se reproduzido à medida que ampliamos nossa amostragem de escolas, e indicam que os estudantes mais carenciados do espectro social são submetidos a um ensino que, em grande proporção, não favorece a aquisição de conhecimentos e competências científicas. Por outro lado, isto não implica em afirmar que os alunos que frequentam as escolas particulares estejam recebendo um ensino de melhor qualidade, mas o que foi possível perceber até o momento é a presença, nestas escolas, de condições mais auspiciosas para a reorientação de determinadas características da prática pedagógica.

O número de aulas semanais para a disciplina nas escolas resultou ser um elemento chave para o ritmo da prática pedagógica, pois as escolas que possibilitam mais aulas permitem que os professores diminuam este ritmo, possibilitando uma maior densidade de intercâmbios entre professor e alunos e, em consequência, diálogos mais ricos e explicações mais detalhadas dos conteúdos e das atividades que os estudantes devem desenvolver para ter êxito na matéria. O estímulo à maior participação dos aprendizes na aula, por meio de questionamentos, a explicitação dos critérios de avaliação e a adoção de um controle menos impositivo e mais pessoal constituem alguns dos resultados que indicaram elevar o desempenho de todos os estudantes, inclusive daqueles mais carenciados. As pressões pelo cumprimento de um extenso currículo, no entanto, atuam desfavoravelmente para a adoção de práticas com estas características. Em um momento que se discute a adoção de um currículo de base nacional no Brasil, esse resultado tem implicações muito diretas com as políticas públicas educacionais.

O modelo de formação inicial dos professores de Química também representa um importante fator para a concepção de práticas pedagógicas uniformes, que desconsideram os diferentes contextos sociais e a necessidade de reorientar o ensino de maneira mais conforme às necessidades dos estudantes. A ênfase nos conteúdos disciplinares e a baixa adesão e reconhecimento dos conhecimentos didáticos e pedagógicos durante a formação concorrem para que os professores percebam a própria instância da prática como o espaço para o desenvolvimento de seu profissionalismo, em detrimento dos saberes teóricos da Didática e da Pedagogia. Essa condição parece levá-los a adotar práticas inspiradas em "modelos universais" de docência, sem levar em conta a singularidade da matéria ensinada, e em reproduzir padrões conservadores e tradicionais no ensino.

As pesquisas que apresentamos foram baseadas em um marco teórico Bernsteiniano e em seu desenvolvimento realizado pelo grupo ESSA. A incorporação de um marco teórico estrangeiro para o contexto brasileiro não pode ser realizado sem uma reflexão, pois nosso contexto social distancia-se enormemente da Inglaterra da segunda metade do século 20, e nossas escolas seguem padrões de organização e de segregação sociais diferentes das escolas portuguesas, onde o grupo ESSA conduz suas próprias investigações. A noção de pedagogia mista e sua incorporação em nossa pesquisa, por exemplo, é um caso que mereceu cuidado de nossa parte, pois como afirmamos anteriormente, a escola pública brasileira raramente constitui um espaço de encontro entre estudantes que pertencem a classes sociais diferentes.

Os conceitos teóricos escolhidos e sua operacionalização analítica em nossa pesquisa, no entanto, proporcionaram os subsídios para a caracterização e comparação entre as 
práticas pedagógicas dos professores de Química, evidenciando suas debilidades, mas também demonstrando suas fortalezas, como as que foram ressaltadas por meio do estudo de intervenção. A escolha pelo estudo das regras discursivas e hierárquicas, privilegiando o discurso instrucional, entretanto, nos conduziu a uma mirada muito centrada na dimensão interacional das práticas de ensino de Química, negligenciando a dimensão epistêmica. Se por um lado, toda pesquisa está condicionada por escolhas teóricas e metodológicas que ampliam nossa visão em determinadas direções enquanto ocultam outras, e a nossa não poderia escapar dessa circunstância, por outro, essa consideração nos indica uma nova direção a assumir daqui em diante.

Os resultados de nosso programa de pesquisa apresentaram as orientações privilegiadas das práticas pedagógicas dos professores de Química observados, que indicam, em especial, as regras para a participação nos intercâmbios que influenciam o desempenho dos estudantes em suas aulas. Entretanto, suas práticas também distribuem diferentes formas de conhecimento químico, que os indicadores empregados na análise não foram capazes de discernir. Nosso programa de pesquisa necessita desenvolver os instrumentos para captar e caracterizar estas formas de conhecimento que são distribuídas aos estudantes, e associá-las a questões de equidade. Esperamos com este novo rumo de nosso programa, ainda que de forma modesta, contribuir para o importante debate sobre justiça social, democracia e educação científica.

\section{Referências}

BERNSTEIN, B. Poder, educación y conciencia: sociología de la trasmisión cultural. Barcelona: El Roure, 1990.

BERNSTEIN, B. Class, codes and control. Volume IV: The structuring of pedagogic discourse. New York: Routledge, 2003.

BOHLMANN, N.; GELLERT, U.; STRAEHLER-POHL, H. Investigando las desigualdades sociales en aulas de matemáticas: logros y expectativas. Didacticae, n. 1, p. 26-44, 2017.

BOURDIEU, P. Las estrategias de la reproducción social. Buenos Aires: Siglo Veintiuno, 2013.

MAINARDES, J.; STREMEL, S. A teoria de Basil Bernstein e algumas de suas contribuições para as pesquisas sobre políticas educacionais e curriculares. Revista Teias, v. 11, n. 22, p. 3154, 2010. Disponível em <<http://www.e-publicacoes.uerj.br/index.php/revistateias/ article/view/24114/17092 > > . Acesso em 18/09/2017.

MORAIS, A. M.; NEVES, I. P. Pedagogic social contexts: studies for a sociology of learning. In: MORAIS, A.M. et al. (eds.). Towards a sociology of pedagogy: the contribution of Basil Bernstein to research. New York: Peter Lang, 2001. p. 185-221.

MORAIS, A. M.; NEVES, I. P. A teoria de Basil Bernstein: alguns aspectos fundamentais. Práxis Educativa, v. 2, n. 2, p. 115-130, 2007.

MORAIS, A. M.; NEVES, I. P. Vertical discourses and Science education: analyzing conceptual demand of educational texts. In: VITALE, P.; EXLEY, B. (Eds.). Pedagogic rights and democratic education: Bernsteinian explorations of curriculum, pedagogy and assessment. London: Routledge, p. 174-191, 2016. 
ROSÁRIO, D. G.; DINIZ, C. W. P. Panorama da educação brasileira: contribuições para uma política baseada em evidências. AMAZÔNIA: Revista de Educação em Ciências e Matemática, v. 5, n. 9-10, p. 48-57, 2008.

SANTOS, A. B. Caracterização de uma prática pedagógica de Química no Ensino Médio: aproximações e distanciamentos em torno da pedagogia mista. 2016. 156 f. Dissertação. (Mestrado em Educação Científica e Formação de Professores). Programa de PósGraduação em Educação Científica e Formação de Professores, Universidade Estadual do Sudoeste da Bahia, Jequié, 2016.

SANTOS, A. B.; TRINDADE, J. S.; SANTOS, B. F. Regras de sequência e de ritmo na prática pedagógica de Química: considerações sobre o conceito de pedagogia mista. In: XVIII ENEQ: Encontro Nacional de Ensino de Química. Anais...Florianópolis, 2016.

SANTOS, B. A aquisição de saberes e competências didáticas no estágio supervisionado da formação do professor de Química. 2017. 208 f. Dissertação. (Mestrado em Educação Científica e Formação de Professores). Programa de Pós-Graduação em Educação Científica e Formação de Professores, Universidade Estadual do Sudoeste da Bahia, Jequié, 2017.

SANTOS, B.; SANTOS, B. F. Aquisição de saberes e competências didáticas no estágio supervisionado da formação do professor de Química: um estudo baseado nas regras discursivas. Enseñanza de las Ciencias, v. 35, n. extraordinário, p. 2343-2347, 2017.

SANTOS, B. F. Contribuições da sociologia de Basil Bernstein para a pesquisa sobre linguagem e interações discursivas nas aulas de ciências. In: SANTOS, B. F.; SÁ, L. P. (Orgs.). Linguagem e ensino de ciências: ensaios e investigações. ljuí: Editora da Unijuí, 2014, p. 5566.

SANTOS, B.F.; SANTOS, K. N.; SILVA, E. S. Interações discursivas em aulas de Química ao redor de atividades experimentais:uma análise sociológica. Ensaio: Pesquisa em Educação em Ciências, v. 16, n. 3, p. 227-246, 2014.

SANTOS, K. S. A instrução da tarefa: uma análise de aulas de Química como contribuição à modelização do ensino.2015. 177 f. Dissertação. (Mestrado em Educação Científica e Formação de Professores). Programa de Pós-Graduação em Educação Científica e Formação de Professores, Universidade Estadual do Sudoeste da Bahia, Jequié, 2015.

SANTOS, L. L. C. P. Bernstein e o campo educacional: relevância, influências e incompreensões. Cadernos de Pesquisa, n. 120, p. 15-49, 2003.

SILVA, E. S. A remodelagem de uma prática pedagógica em torno das regras discursivas e hierárquicas no ensino de Química: contribuições da sociologia de Basil Bernstein. 2015. 310 f. Dissertação. (Mestrado em Educação Científica e Formação de Professores). Programa de Pós-Graduação em Educação Científica e Formação de Professores, Universidade Estadual do Sudoeste da Bahia, Jequié, 2015.

SILVA, E. S.; SANTOS, B. F. El remodelado de una práctica pedagógica de Química que altera características sociológicas. In: LORENZO, M. G.; ODETTI, H. S. (Orgs.). Comunicando la ciencia. Avances en investigación en didáctica la ciencia.Santa Fe: Ediciones UNL, 2018, p. 37-54. 
SILVA, R. L.; SOUZA, G. M. S.; SANTOS, B. F. Questionamentos em aulas de Química: um estudo comparativo da prática pedagógica em diferentes contextos sociais. Revista Brasileira de Pesquisa em Educação em Ciências, v. 18, n. 1, 2018 (No prelo).

SOUZA, G. M. S.; SANTOS, B. F. The influence of social context in the pedagogical practice of a chemistry teacher. In: 12th ESERA: European Science Education Research Association. Proceedings... Helsinki, 2016.

SOUZA, R. V. Professores de Química que também lecionam Física: um estudo comparativo sobre a prática pedagógica. 2017. 206 f. Dissertação. (Mestrado em Educação Científica e Formação de Professores). Programa de Pós-Graduação em Educação Científica e Formação de Professores, Universidade Estadual do Sudoeste da Bahia, Jequié, 2017.

SOUZA, R. V.; SILVA, R. L.; SANTOS, B .F. Intradisciplinaridade e interdisciplinaridade na prática pedagógica de um professor licenciado em Química que também leciona Física. In: XI ENPEC: Encontro Nacional de Pesquisa em Educação em Ciências. Anais...Florianópolis, 2017. 